\title{
ANALISIS SALURAN DISTRIBUSI DAN MARGIN PEMASARAN TELUR ITIK DI KABUPATEN SITUBONDO
}

\author{
Latifatul Hasanah', Ujang Suryadi², Wahjoe Widhijanto² \\ ${ }^{1}$ Manajemen Bisnis Unggas, Politeknik Negeri Jember \\ 2Jurusan Perternakan, Politeknik Negeri Jember \\ Email: latifah.fatul.awu@gmail.com
}

\section{INTISARI}

Penelitian ini bertujuan untuk mengetahui distribusi dan margin pemasaran telur itik di Kabupaten Situbondo. Metode yang digunakan untuk menggumpulkan data ialah survei dengan bantuan kuesioner dan wawancara. Hasil penelitian menunjukkan analisis efisiensi pemasaran pada distribusi panjang dan pendek masing-masing sebesar 2,84\% dan 1,16\%. Saluran distribusi pendek lebih efisien dibandingkan dengan saluran distribusi panjang, sehingga saluran distribusi pendek memberikan keuntungan yang lebih besar bagi pelaku pemasaran telur itik di Kabupaten Situbondo.

Kata kunci : Saluran Distribusi, Telur Itik, Keuntungan Pemasaran

\section{ABSTRACT}

This study aims to find out the distribution and marketing margins of duck eggs in Situbondo. The methods used to collect data were survey and interviews suported by questionnaires. The analisys of short and long distribution channels showed were $2.84 \%$ and $1.16 \%$ respectively. The short distribution channel was more efficient than long distributin channel, so that it provided greater benefits for marketing of duck eggs in Situbondo.

Keyword: Distribution Channels, Duck Eggs, Marketing Margins

\section{PENDAHULUAN}

\section{Latar Belakang}

Usaha peternakan itik merupakan salah satu usaha peternakan yang cukup berperan dalam perekonomian. Hasil produksi itik berupa telur dan daging yang dapat di konsumsi serta banyak diminati oleh masyarakat (Kurnianingrum, 2008).

Produksi telur itik di Kabupaten Situbondo mengalami peningkatan dari $382.246 \mathrm{~kg}$ pada tahun 2013 (BPS, 2013) menjadi 385.708 kg (BPS, 2014). Produsen telur dalam memasarkan telur itik menggunakan berbagai cara agar produk telur itik sampai ke tangan konsumen. Pemasaran ini membutuhkan proses yang panjang dan biaya yang tinggi. Salah satu bentuk usaha untuk mencapai tujuan dan sasaran dibidang pemasaran adalah dengan kegiatan pemilihan saluran pemasaran. Semakin panjang rantai pemasaran biasanya semakin tinggi biaya pemasaran, dan semakin tidak efisien.

Biaya pemasaran ini sering kali diukur dengan margin pemasaran yaitu bagian yang dibayarkan konsumen ketika membeli produk atau barang yang diperlukan untuk menutupi biaya yang dikeluarkan dalam proses pemasaran (Kotler, 2005). 


\section{Tujuan Penelitian}

Penelitian ini bertujuan untuk mengetahui bentuk saluran distribusi pemasaran telur itik dan mengetahui saluran pemasaran telur itik yang lebih efisien di Kabupaten Situbondo.

\section{MATERI DAN METODE}

Penelitian ini merupakan penelitian diskriptif dengan menggunakan metode survei. Metode pengambilan sampel dalam penelitian ini yaitu secara purpossive sampling, yaitu penentuan lokasi penelitian dengan cara sengaja. Sampel yang di gunakan sebanyak 50 responden yang terdiri dari 15 peternak, 10 pedagang pengepul, 25 pedagang pengecer. Data yang diambil merupakan data primer dan data sekunder. Data primer diambil menggunakan kuesioner dengan metode wawancara, sedangkan data sekunder diambil dari data Badan Pusat Statistik. Data yang diperoleh dianalisis secara diskriptif, sedangkan margin pemasaran dianalisis menggunakan analisis margin pemasaran dan distribusi margin pemasaran yang diterima masing-masing pemasaran menggunakan rumus menurut Sudiyono (2002).

$$
\mathrm{Mp}=\operatorname{Pr}-\mathrm{Pf}
$$

\section{Keterangan:}

$\mathrm{Mp}=$ Margin pemasaran (Rp/butir)

$\operatorname{Pr}=$ Harga penjualan (Rp/butir)

Pf = Harga pembelian (Rp/butir)
Margin pemasaran setiap model saluran pemasaran yang terlibat digunakan rumus Menurut Swasta (1999).

$\mathrm{Mt}=\mathrm{M} 1+\mathrm{M} 2 \ldots \ldots \ldots+\mathrm{Mn}$

Keterangan:

Mt = Margin pemasaran total

M1 = Margin pemasaran lembaga pemasaran ke-1

M2 = Margin pemasaran lembaga pemasaran ke-2

$\mathrm{Mn}=$ Margin pemasaran lembaga pemasaran ke-n

Analisis efisiensi pemasaran dilihat dari share harga yang diterima produsen menurut Fanani (2002).

$$
\mathrm{Ep}=\frac{\mathrm{BP}}{\mathrm{NP}} \times 100 \%
$$

Keterangan:

Ep = Efisiensi pemasaran (\%)

$\mathrm{BP}=$ Total biaya pemasaran $(\mathrm{Rp} /$ butir $)$

$\mathrm{NP}=$ Total nilai produk yang dipasarkan (Rp/butir)

Jika Ep nilainya paling kecil maka paling efisien

\section{HASIL DAN PEMBAHASAN}

\section{Saluran Distribusi Pemasaran Telur Itik}

Sistem pemasaran telur itik yang ada di Kabupaten Situbondo sebagian besar melibatkan pedagang pengepul dan pedagang pengecer, hal ini disebabkan oleh rendahnya tingkat pengetahuan peternak dalam proses pemasaran telur itik serta lebih efisien waktu dan biaya. Hasil pengamatan dan penelusuran diketahui bahwa pemasaran telur itik di Kabupaten Situbondo seperti pada Gambar 1. 


\section{Analisis Saluran Pemasaran}

Saluran pemasaran merupakan komponen penting dalam pemasaran barang dan jasa, berdasarkan penelitian yang telah dilakukan, pemasaran telur itik di Kabupaten Situbondo terdapat 2 saluran distribusi yaitu saluran distribusi panjang dan saluran distribusi pendek. Adapun bentuk saluran distribusi tertera pada Gambar 2.

\section{Saluran Distribusi Panjang}

Saluran distribusi panjang merupakan saluran pemasaran telur itik yang menggunakan dua pedagang perantara yaitu pedagang pengumpul dan pedagang pengecer. Saluran pemasaran ini di mulai dari peternak ke pedagang pengumpul, selanjutnya pedagang pengecer, dan terakhir konsumen.

Harga jual telur itik pada pedagang pengepul Rp1.420,00/butir dan harga beli Rp1.160,00/butir, sehingga margin pemasaran yang didapat oleh pedagang pengepul adalah Rp260,00/butir, sedangkan harga jual telur itik pada pedagang pengecer Rp1.790,00/butir dan harga beli Rp1.420,00/butir, sehingga margin pemasaran yang diperoleh pedagang pengecer adalah Rp370,00/butir. Margin pemasaran pada saluran distribusi panjang terdapat dua margin pemasaran yaitu margin pemasaran pedagang pengepul Rp260,00/butir dan margin pemasaran pedagang pengecer Rp370,00/butir, sehingga margin pemasaran saluran distribusi panjang di Kabupaten Situbondo adalah Rp630,00/butir.

Biaya penjualan telur itik yang dikeluarkan oleh pedagang pengepul pada saluran distribusi panjang sebesar Rp37,75/butir dan biaya pedagang pengecer sebesar Rp13.41/butir, sehingga biaya pemasaran telur pada saluran distribusi panjang di Kabupaten Situbondo adalah Rp51,16/butir.

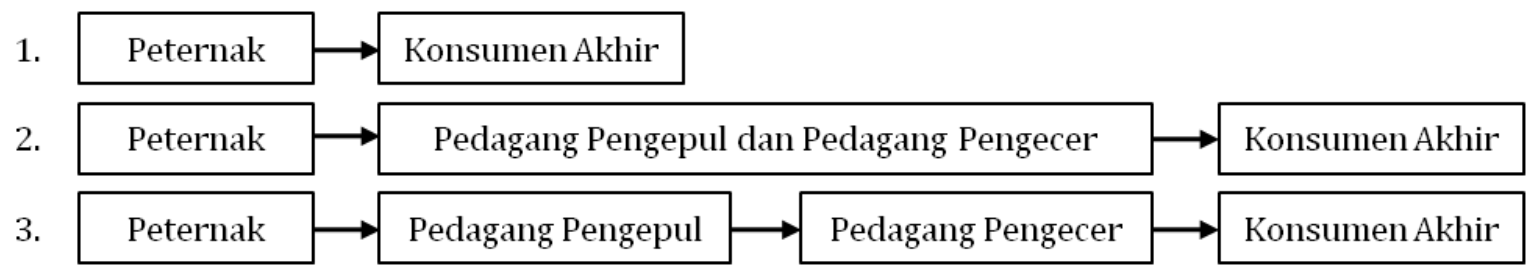

Gambar 1. Bentuk saluran distribusi pemasaran.

Keuntungan yang dicapai pada keuntungan yang diperoleh pada saluran pedagang pengepul yaitu Rp222,25/butir yang distribusi panjang yaitu Rp579,25/butir, yang didapat dari harga jual telur itik dikurangi artinya dalam setiap butir telur itik yang dengan harga beli telur dan biaya pemasaran terjual keuntungan yang diperoleh adalah telur, sedangkan keuntungan yang dicapai sebesar Rp579,25. pedagang pengecer pada saluran distribusi pendek yaitu Rp357,00/butir, sehingga 
Saluran Distribusi Pendek

Saluran distribusi pendek merupakan saluran pemasaran telur itik yang hanya menggunakan satu pedagang perantara yaitu pedagang pengepul, pada saluran ini peternak menjual ke pedagang pengepul dan pedagang pengepul ke konsumen.
Margin pemasaran pada Gambar 2. diperoleh dari harga jual dikurangi dengan harga beli, harga jual telur pedagang pengecer pada saluran distribusi pendek Rp1.700,00/butir dengan harga beli Rp1.120,00/butir, sehingga margin pemasaran pada saluran distribusi pendek yaitu Rp580,00/butir.

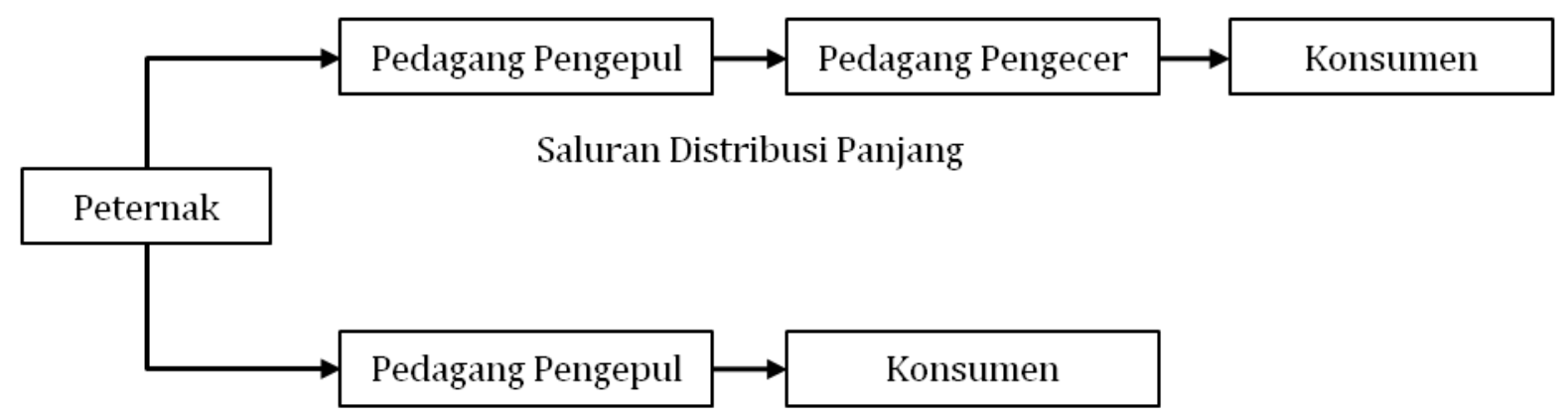

Saluran Distribusi Pendek

Gambar 2. Saluran pemasaran telur itik di Kabupaten Situbondo.

Biaya pemasaran saluran distribusi yang didapat dari harga jual telur itik pendek Rp19,75/butir, biaya tersebut dikurangi dengan harga beli dan biaya merupakan biaya yang dikeluarkan untuk penjualan telur itik. Keuntungan yang didapat memasarkan telur itik di Kabupaten pada saluran distribusi pendek cukup tinggi, Situbondo, artinya pada saluran distribusi hal ini dikarenakan biaya yang dekeluarkan pendek dalam setiap satu butir telur untuk menjual telur itik tidak terlalu besar, membutuhkan biaya pemasaran $\mathrm{Rp} 19,75$. saluran distribusi pendek hanya Biaya pemasaran pada saluran distribusi lebih menggunakan satu perantara dalam sedikit dikarenakan pedagang pengecer hanya mengeluarkan biaya transportasi untuk membeli telur ke peternak dan melakukan pemasaran di pasar. Hal ini sesuai dengan pendapat Rasyaf (1999) besar kecilnya biaya pemasaran yang dikeluarkan tergantung dari panjang pendeknya jalur pemasaran dan peran fungsi tata niaga.

Keuntungan pedagang pengecer pada saluran distribusi pendek Rp560,25/butir, memasarkan telur itik sehingga keuntungan yang diperoleh sangat tinggi.

Daniel (2002) yang menyatakan bahwa semakin panjang jarak dan semakin banyak perantara yang terlibat dalam pemasaran, maka biaya pemasaran semakin tinggi dan margin tata niaga juga semakin besar. Menurut Hanafiah dan Saefuddin (1986) bahwa semakin jauh daerah konsumen terhadap daerah produksi maka semakin 
besar biaya tata niaga. Jika perbedaan distribusi biaya pada masing-masing saluran distribusi pemasaran semakin besar, maka saluran distribusi pemasaran dikatakan semakin tidak efisien (Supriyono, 1998).

\section{Analisis Efisiensi Saluran Distribusi Pemasaran}

Efisiensi pemasaran terjadi bila biaya pemasaran dapat ditekan sehingga keuntungan pemasaran dapat lebih tinggi.
Adapun efisiensi pemasaran pada lembaga pemasaran saluran distribusi panjang dan pendek disajikan pada Tabel 1.

Hasil analisis efisiensi pemasaran menunjukkan bahwa efisiensi saluran distribusi panjang yaitu 2,84\% dan saluran distribusi pendek yaitu 1,16\%, saluran pemasaran telur itik yang memiliki nilai efisiensi terkecil adalah saluran distribusi pendek.

Tabel 1. Efisiensi Saluran Pemasaran

Efisiensi Pemasaran Telur Itik

\begin{tabular}{cccc}
\hline $\begin{array}{c}\text { Saluran } \\
\text { Distribusi }\end{array}$ & $\begin{array}{c}\text { Biaya Pemasaran } \\
\text { (Rp/butir) }\end{array}$ & $\begin{array}{c}\text { Nilai Produk yang } \\
\text { Dipasarkan (Rp/butir) }\end{array}$ & Efisiensi Pemasaran (\%) \\
\hline Panjang & $(\mathrm{a})$ & $(\mathrm{b})$ & $(\mathrm{a}: \mathrm{b}) \mathrm{x} 100$ \\
Pendek & 51,16 & $1.800,00$ & 2,84 \\
\hline
\end{tabular}

Hal ini dikarenakan saluran distribusi pendek tidak mengeluarkann biaya yang besar, yaitu Rp19,75/butir dengan harga jual telur itik pada konsumen sebesar Rp1.700,00/butir. Biaya pemasaran pada saluran distribusi panjang Rp51,16/butir dengan harga jual telur itik pada konsumen Rp1.800,00/butir. Saluran distribusi pendek dalam hal ini merupakan saluran distribusi yang lebih efisien dibandingkan dengan saluran distribusi panjang. Hal tersebut sesuai dengan pendapat Dilon (2008) yang menyatakan bahwa semakin tinggi biaya pemasaran akan menunjukkan semakin rendahnya efisiensi sistem pemasarannya. Lebih lanjut dinyatakan oleh Downey dan Erickson, (1992) bahwa semakin panjang rantai pemasaran yang digunakan oleh suatu lembaga akan semakin tidak efisien.
Hasil analisis yang didapat dari analisis margin pemasaran adalah saluran distribusi panjang memiliki margin pemasaran yang paling besar yaitu Rp630,00/butir dengan biaya yang dikeluarkan sebesar Rp51,16/butir dan keuntungan yang diperoleh yaitu Rp579,25/butir. Saluran distribusi pendek memiliki margin pemasran yang lebih kecil yaitu Rp580,00/butir dengan biaya yang dikeluarkan sebesar Rp19,75/butir dan keuntungan yang diperoleh yaitu Rp560,25/butir. Analisis efisiensi pemasaran menunjukkan bahwa efisiensi saluran distribusi panjang sebesar 2,84\% dan saluran distribusi pendek sebesar 1,16\% (Tabel 1). Hal ini menunjukkan bahwa saluran pemasaran telur itik yang memiliki nilai efisiensi terkecil terdapat pada saluran distribusi pendek. 
Hasil uji dan analisis margin pemasaran menunjukkan bahwa saluran distribusi berpengaruh terhadap hasil atau keuntungan pemasaran telur itik. Saluran distribusi pendek lebih efisien dibandingkan dengan saluran distribusi panjang, sehingga saluran distribusi pendek memberikan keuntungan yang lebih besar bagi pelaku pemasaran telur itik di Kabupaten Situbondo.

\section{KESIMPULAN DAN SARAN}

\section{Kesimpulan}

Saluran distribusi pendek lebih efisien dibandingkan dengan saluran distribusi panjang, sehingga saluran distribusi pendek memberikan keuntungan yang lebih besar bagi pelaku pemasaran telur itik di Kabupaten Situbondo.

\section{Saran}

Penelitian lebih lanjut perlu dilakukan untuk mengetahui variabel lain yang berpengaruh terhadap efisiensi saluran distribusi panjang maupun saluran distribusi pendek.

\section{DAFTAR PUSTAKA}

Badan Pusat Statistik (BPS). 2013. https://jatim.bps.go.id/linkTabelStatis/ view/id/52. Diakses tanggal 30 Oktober 2015.

Badan Pusat Statistik (BPS). 2014. https://jatim.bps.go.id/linkTabelStatis/ view/id/550. Diakses tanggal 30 Oktober 2015.
Daniel, M. 2002. Pengantar Ekonomi Pertanian. Penerbit Bumi Aksara. Jakarta.

Dillon, H.S. 2008 Manajemen Distribusi Produk- Produk Agroindustri. Percetakan TI-ITS. Jakarta.

Downey, W.D. dan S.P. Erickson. 1989. Manajemen Agribisnis. Erlangga. Jakarta.

Hanafiah, A.M. dan A.M. Saefuddin. 1986. Tata niaga Hasil Perikanan. Universitas Indonesia Press. Jakarta.

Kotler, P. 2005. Manajemen Pemasaran. Jilid I. PT. Indeks Kelompok Gramedia. Jakarta.

Kurnianingrum, A.R. 2008. Analisis saluran dan marjin pemasaran studi empirik komoditas telur ayam ras. Jurnal Ekonomi dan Bisnis. 9(2).

Rasyaf, M. 1999. Memasarkan Hasil Peternakan. Penebar Swadaya. Jakarta.

Sudiyono, A. 2002. Pemasaran Pertanian. UMM Press. Malang.

Supriyono, A. 1998. Pengantar Tata Niaga Pertanian Teori dan Aplikasi. Faperta UNEJ. Jember.

Swasta, B dan Sukotjo. 1999. Pengantar Bisnis Modern. Liberty. Yogyakarta 